\title{
A novel role of MNT as a negative regulator of REL and the NF-KB pathway
}

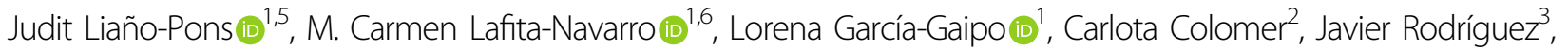
Alex von Kriegsheim ${ }^{3,7}$, Peter J. Hurlin $\mathbb{1}^{4}$, Fabiana Ourique ${ }^{1,8}$, M. Dolores Delgado ${ }^{1}$, Anna Bigas ${ }^{2}$, Lluis Espinosa ${ }^{2}$ and Javier León (10 ${ }^{1}$

\begin{abstract}
MNT, a transcription factor of the MXD family, is an important modulator of the oncoprotein MYC. Both MNT and MYC are basic-helix-loop-helix proteins that heterodimerize with MAX in a mutually exclusive manner, and bind to E-boxes within regulatory regions of their target genes. While MYC generally activates transcription, MNT represses it. However, the molecular interactions involving MNT as a transcriptional regulator beyond the binding to MAX remain unexplored. Here we demonstrate a novel MAX-independent protein interaction between MNT and REL, the oncogenic member of the NF-KB family. REL participates in important biological processes and it is altered in a variety of tumors. REL is a transcription factor that remains inactive in the cytoplasm in an inhibitory complex with IKB and translocates to the nucleus when the NF-KB pathway is activated. In the present manuscript, we show that MNT knockdown triggers REL translocation into the nucleus and thus the activation of the NF-KB pathway. Meanwhile, MNT overexpression results in the repression of $1 \mathrm{kBa}$, a bona fide REL target. Both MNT and REL bind to the IkBa gene on the first exon, suggesting its regulation as an MNT-REL complex. Altogether our data indicate that MNT acts as a repressor of the NF-KB pathway by two mechanisms: (1) retention of REL in the cytoplasm by MNT interaction, and (2) MNT-driven repression of REL-target genes through an MNT-REL complex. These results widen our knowledge about MNT biological roles and reveal a novel connection between the MYC/MXD and NF-KB pathways, two of the most prominent pathways in cancer.
\end{abstract}

\section{Introduction}

MNT is a protein from the MYC/MAX/MXD/MLX network of transcription factors, which has a pivotal role in controlling cell proliferation, differentiation, metabolism, and oncogenic transformation. MNT is a basichelix-loop-helix leucine zipper (bHLHLZ) protein that regulates transcription as heterodimers with $\mathrm{MAX}^{1,2}$ or MLX $^{3}$ but also as homodimers ${ }^{4}$. Hence MNT connects the MYC-MAX and MLX-Mondo branches of the network ${ }^{5}$. MNT normally represses gene transcription by binding to

\footnotetext{
Correspondence: Javier León (leonj@unican.es)

'Departmento de Biología Molecular, Instituto de Biomedicina y Biotecnología de Cantabria (IBBTEC), CSIC-Universidad de Cantabria, Santander, Spain

${ }^{2}$ Cancer Research Program, Institut Hospital del Mar d'Investigacions Mèdiques, CIBERONC, Hospital del Mar, Barcelona, Spain

Full list of author information is available at the end of the article
}

E-boxes and interacting with SIN3 proteins that, in turn, recruit histone deacetylase complexes to its target genes ${ }^{1,6}$.

Among the MXD proteins, MNT is the biggest as well as the most ubiquitously expressed and conserved member ${ }^{7,8}$. Whereas $M x d 1^{-1-}, M x i 1^{-1-}$, and $M x d 3^{-/-}$mice survive, mice knockout for Mnt die soon after birth ${ }^{9-12}$. Thus, MNT is a unique and essential protein of this network. MNT is also frequently deleted in cancer, e.g., in chronic lymphocytic leukemia, Sézary syndrome (a variant of cutaneous T-cell lymphoma), and medulloblastoma ${ }^{13-16}$. Indeed, around $10 \%$ of the tumors show deletions of an MNT allele ${ }^{17}$.

MNT has an important role in modulating the oncogenic activities of MYC whether as an antagonist and tumor suppressor or as a cooperator ${ }^{7}$. MNT-MYC antagonism is achieved at three different levels:

\section{(c) The Author(s) 2021, corrected publication 2021}

\footnotetext{
(c) (i) Open Access This article is licensed under a Creative Commons Attribution 4.0 International License, which permits use, sharing, adaptation, distribution and reproduction in any medium or format, as long as you give appropriate credit to the original author(s) and the source, provide a link to the Creative Commons license, and indicate if changes were made. The images or other third party material in this article are included in the article's Creative Commons license, unless indicated otherwise in a credit line to the material. If material is not included in the article's Creative Commons license and your intended use is not permitted by statutory regulation or exceeds the permitted use, you will need to obtain permission directly from the copyright holder. To view a copy of this license, visit http://creativecommons.org/licenses/by/4.0/.
} 
(i) competition for binding to MAX; (ii) competition between MNT-MAX and MYC-MAX for binding to the E-Boxes of their shared target genes; (iii) transcriptional repression of shared target genes that are normally activated by MYC-MAX ${ }^{9,10}$. This antagonism can explain why the deletion of MNT leads to tumor formation in mouse mammary epithelium and T-cells ${ }^{9,10}$. However, other studies suggest that MYC needs the pro-survival functions of MNT for fully achieving its transformation potential. This is the case of MYC-driven B- and T-cell lymphoma models, where MNT deficiency impairs MYCdriven tumorigenesis ${ }^{9,10,18}$.

Nevertheless, there are several unsolved questions about the MNT mechanism of action. All the functions described so far for MNT have been attributed to MNT-MAX dimers. However, MAX is deleted in some cancers, as pheochromocytoma, paraganglioma, gastrointestinal stromal tumors, and small cell lung cancer ${ }^{19-21}$. Moreover, we have recently described MAX-independent MNT activities in cell proliferation and gene transcription ${ }^{4}$. Thus, we hypothesized that there are MNT functions dependent on the interaction with other proteins different from MAX. In this work, we have investigated new MNT interactions in a MAX-independent setting and identified c-REL (REL hereafter), a member of the NF-kB's family, as an MNT interacting protein. NF- $\mathrm{kB}$ signaling pathway has a major role in proliferation, differentiation, and apoptosis, particularly in cells from the immune system ${ }^{22,23}$. REL was first described by homology with v-rel, the oncogene from the avian reticuloendotheliosis virus ${ }^{24}$. Importantly,
REL is the only NF-kB protein with transforming ability ${ }^{25}$ and is altered in a variety of tumors ${ }^{26}$. In the present manuscript, we show that MNT deletion leads to (1) translocation of REL into the nucleus and activation of the NF-kB pathway, and (2) REL-dependent inhibition of cell proliferation. This suggests that MNT maintains cell survival through the regulation of the NF- $\kappa B$ pathway. Moreover, MNT-REL complexes bind to an NF- $k B$ target gene, $N F K B I A / \mathrm{I} \kappa \mathrm{B} \alpha$, a protein required to retain NF- $\kappa \mathrm{B}$ dimers in the cytoplasm in the absence of activating stimulus $^{23}$. In summary, this work describes the first evidence of physical interaction between the MYC-MAXMNT and NF- $\mathrm{kB}$ pathways and provides an insight into the relevance of MNT in cell biology.

\section{Results}

\section{Searching for new MNT partners}

To find proteins that interact with MNT in a MAXindependent way, we performed proteomic analysis of MNT immunoprecipitates in UR61-derived cells, which come from a rat pheochromocytoma and lack a functional MAX gene ${ }^{27}$. We used URMax34, a cell line with a $\mathrm{Zn}^{2+}$-inducible MAX allele and its control cells (URMT), which were transfected with the empty vector ${ }^{4}$. MNT was immunoprecipitated by triplicate for each cell line and subjected to mass spectrometry. The results showed 11 proteins that were reproducibly immunoprecipitated in URMT and 47 in URMax34 (Supplementary Table 1). Five proteins were shared between the two cell lines: REL, CCDC6, AMPD2, QSER1, and TPP2 (Fig. 1a). Given the
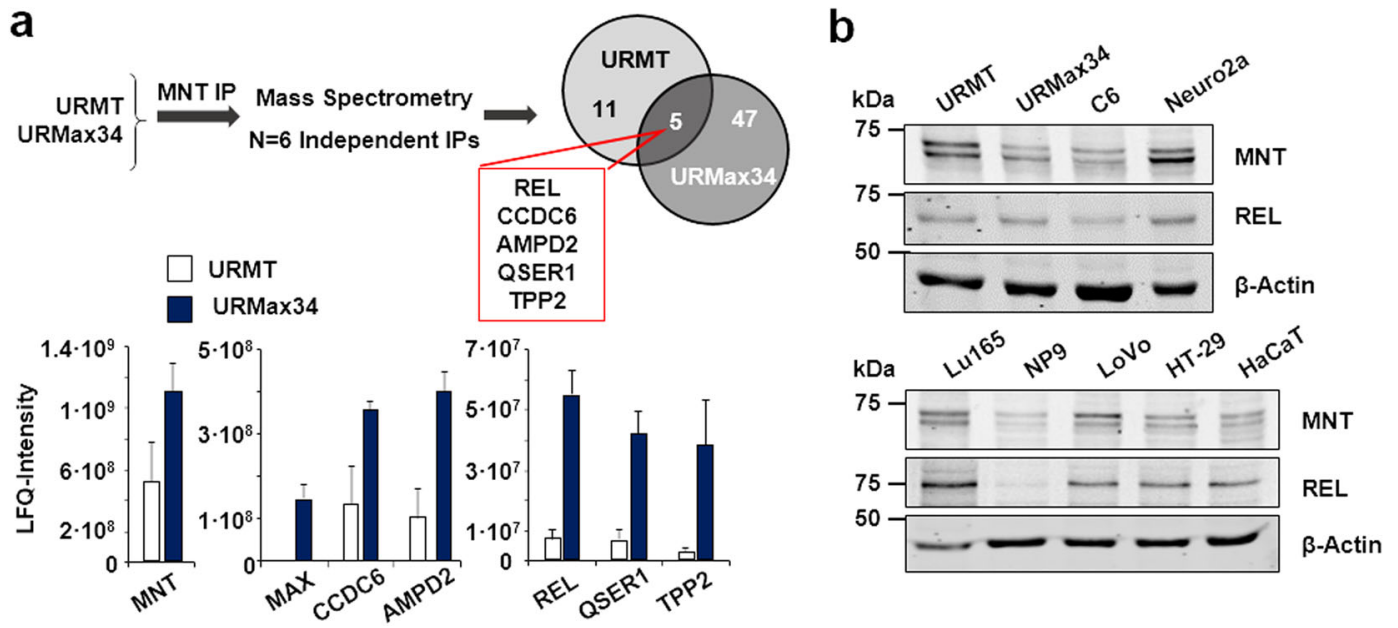

Fig. 1 Proteins interacting with MNT. a Top: Schematic representation of the proteomic study: URMT and URMax34 cells were treated with $100 \mu M$ $\mathrm{Zn}_{2} \mathrm{SO}_{4}$ for $24 \mathrm{~h}$ and lysed for posterior MNT immunoprecipitation. Six independent immunoprecipitations were analyzed by mass spectrophotometry and five proteins were found bound to MNT in URMT and URMax34. Bottom: Quantification of the protein interactions. The bar graphs represent mean LFQ intensity values of the selected MNT interactions \pm S.D. $(n=6) . P<0.05$ with respect to lgG. $\mathbf{b}$ Immunoblot of MNT and REL in different cell lines: URMT (control UR61) and URMax34 (UR61 with MAX expression induced by $\mathrm{Zn}^{2+}$ ); C6 (rat brain glioma); Neuro-2a (mouse neuroblastoma); Lu165 (small cell lung cancer); NP9 (human pancreatic adenocarcinoma); LoVo and HT-29 (human colorectal adenocarcinoma); HaCaT (human keratinocyte). $\beta$-actin levels were determined as a protein loading control. 
relevance of the NF- $\kappa B$ pathway in cell biology, we selected REL for further studies. First, we tested the protein expression of MNT and REL levels in several cell lines, including URMT and URMax34 cells, by western blot (Fig. 1b). As we recently described, MNT expression was higher in the URMT cells lacking $\mathrm{MAX}^{4}$.

Next, we confirmed MNT-REL interaction by coimmunoprecipitation (co-IP) assays followed by western blot. REL was present in MNT immunoprecipitates of URMax34 cells induced to express MAX. In this model, we confirmed the MNT-MAX co-IP. However, REL was not present in the MAX immunoprecipitates, indicating that there was no interaction of REL with MAX (Fig. 2a). We also found REL-MNT co-IP in mouse Neuro-2a (Fig. 2b), human colon cancer LoVo (Fig. 2c), and rat glioma C6 cells (Fig. 2d, left). MNT-REL interaction was not detected in other cell lines tested, e.g., SH-SY5Y (neuroblastoma), HEK293T (embryonic kidney), K562 (chronic myeloid leukemia), A549 and H1299 (lung cancer), and HEPG2 (hepatocellular carcinoma).

We also detected MNT-REL interaction in immunoprecipitates with anti-REL antibodies in LoVo cells (Fig. 2c), C6 (Fig. 2d), and URMT cells (not shown). Next, we wanted to confirm the interaction between MNT and REL through proximity ligation assays. We transfected C6 cells with MNT and REL expression vectors and obtained a positive result of MNT-REL interaction (Fig. 2e). The interaction was also observed in untransfected LoVo cells, although the signal was less intense (Fig. 2f). The interactions between MYC-MAX and p65-REL were used as positive controls of the assay. MYC-REL and MNT-MYC were used as negative controls.

REL is generally found forming homodimers or heterodimers with $\mathrm{p} 65$ or $\mathrm{p} 50^{22}$. To assess whether there was any p65 or p50 in the MNT-REL complex, we immunoprecipitated p65 to show the p65-REL interaction in UR61 cells with and without MAX. We observed p65-REL interaction but not the p65-MNT co-IP (Fig. 3a). We also performed co-IP assays using two different antibodies against MNT, recognizing the first $1-50$ amino acids and the amino acids 532-582, respectively. In addition, we used antibodies anti-p65 and p105/p50. The results showed that, in LoVo cells, REL co-immunoprecipitated with the anti-MNT antibody recognizing the MNT 1-50 amino acids but not in the anti-MNT recognizing the amino acids $532-582$ (Fig. 3b). The binding of the antibody to the 532-582 amino acids of MNT may disrupt MNT-REL co-IP, which suggests the implication of MNT C-terminal domain in the interaction. MAX co-IP was detected in both MNT immunoprecipitates (positive control) (Fig. 3b). However, neither p65 nor p50 was found to interact with MNT in any of the IPs. REL coimmunoprecipitated with p65 and p50 as expected. Since p65 and p50 did not interact with MNT, it is possible that the MNT-REL complex may be composed of REL homodimers or REL bound to other unknown protein(s), as schematically represented in Fig. 3c.

To determine the domain of MNT involved in the interaction with REL, we used two MNT deletion mutants tagged with the HA epitope: $\triangle \mathrm{bHLH}$ (lacking the bHLH domain, residues 221-272) and $\Delta$ Ct1 MNT-HA (lacking the C-terminal region of 276 residues) (Fig. 3d). We transfected these constructs along with a construct expressing wild-type mouse REL into C6 cells. Interestingly, REL appeared bound to $\triangle \mathrm{bHLH}$ but not to $\Delta \mathrm{Ct} 1$ (Fig. 3e). We repeated this same procedure with two MNT N-terminal deletion constructs, $\Delta \mathrm{Nt1}$ (lacking residues 1-300) and $\Delta \mathrm{Nt} 2 \mathrm{MNT}-\mathrm{HA}$ (lacking 1-271 residues) (Supplementary Fig. S1a). Both $\Delta \mathrm{Nt1}$ MNT-HA and $\triangle \mathrm{Nt} 2 \mathrm{MNT}-\mathrm{HA}$ interacted with REL (Supplementary Fig. S1b). Altogether, these data show that the C-terminal region of MNT is necessary for the formation of MNT-REL complexes, but not its bHLHLZ domain. We also assayed a REL mutant lacking the REL Inhibitory Domain (RID), which is a transactivation inhibitory domain not involved in IKB binding ${ }^{22,28}$ (Supplementary Fig. S1c). The co-IP experiments showed that the deletion of RID abrogated the interaction with MNT (Supplementary Fig. S1d). Thus, the interaction takes place between the MNT C-terminal region and the RID region of REL (Fig. 3d).

Next, we investigated the localization of MNT-REL complexes carrying out a nucleus-cytoplasm fractionation in C6 cells. The co-IP was performed in basal conditions and after $30 \mathrm{~min}$ of stimulation with TNF $\alpha$ (which promotes the translocation of REL to the nucleus) ${ }^{29}$. The results showed that the MNT-REL complex localizes in the cytoplasm in normal conditions but also in the nucleus upon activation of the NF- $\kappa B$ pathway by TNF $\alpha$ (Fig. 3f).

\section{MNT acts as a repressor of the NF-KB's pathway}

We asked whether this novel MNT-REL interaction had any impact on the NF- $\mathrm{kB}$ signaling. As NF- $\mathrm{kB}$ dimers translocate to the nucleus upon the activation of the pathway, we knocked down MNT in LoVo cells and performed immunofluorescence assays for REL and p65 to assess their cellular localization. Strikingly, REL accumulated inside the nucleus after $M N T$ knockdown, suggesting an activation of the pathway. On the contrary, p65 remained in the cytoplasm regardless of MNT levels (Fig. 4a). This was confirmed by densitometry of the REL and p65 immunofluorescence signals (Supplementary Fig. S2). We next asked whether MNT knockdown would cause the release of REL from IкB $\alpha$ by co-IP assays in LoVo cells. The results showed that despite ІкB $\alpha$ levels were increased upon MNT silencing, IKB $\alpha$-REL complexes decreased when compared to the control 


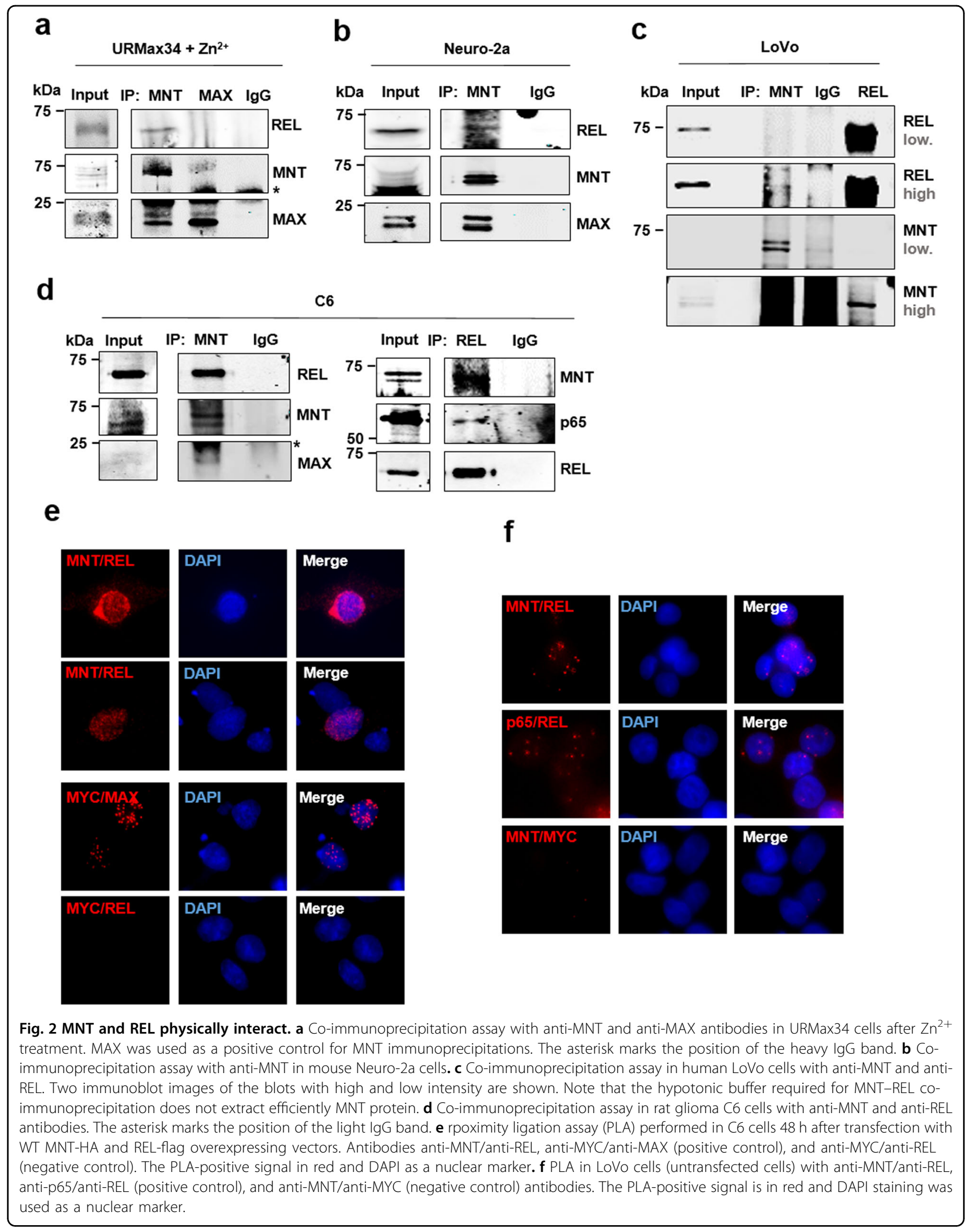


a

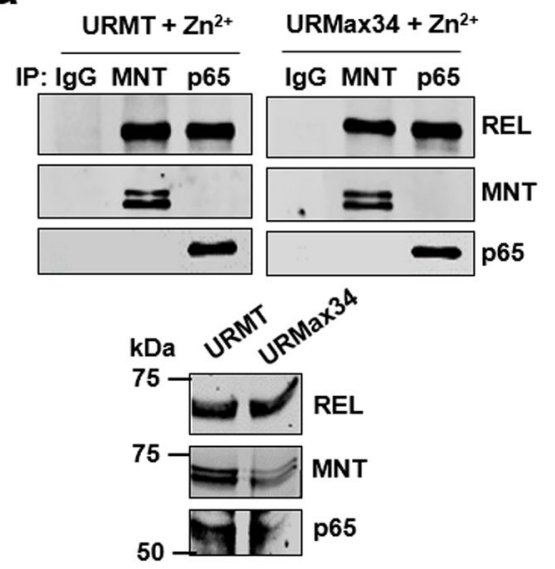

b

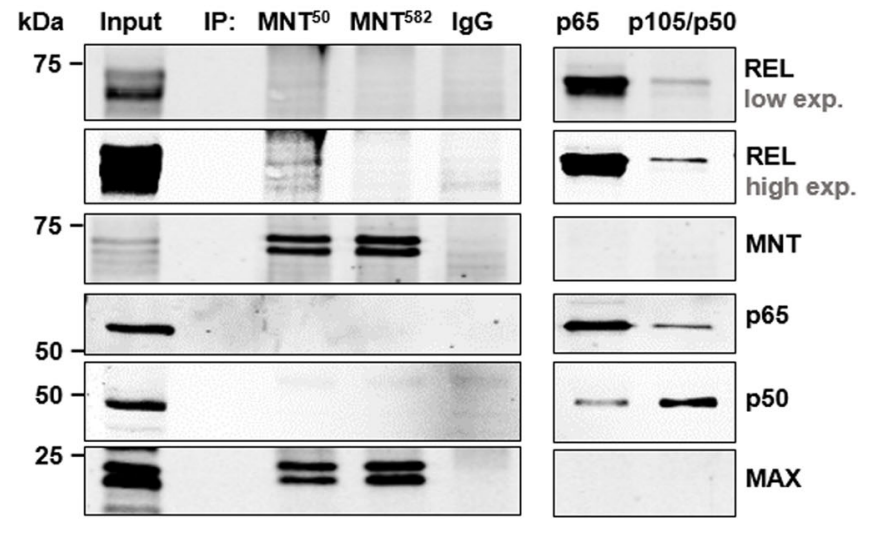

C

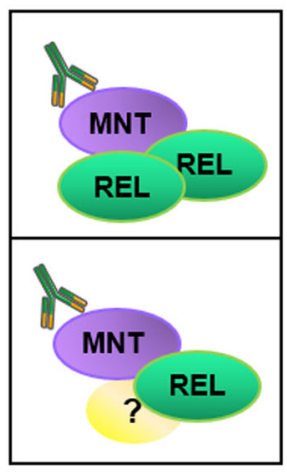

f

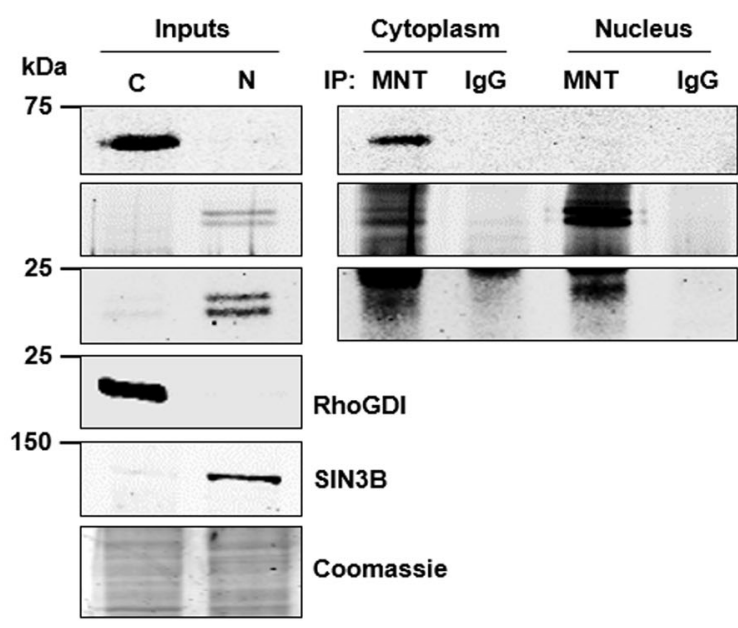

d

e
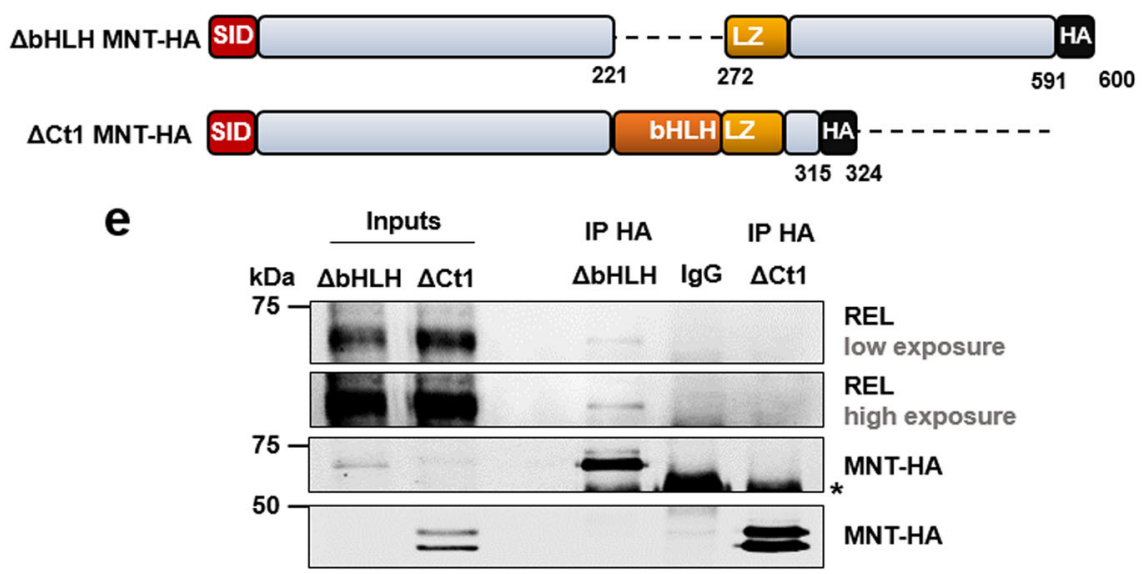

+ TNFa

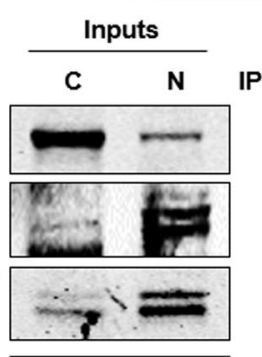

Cytoplasm

IP: MNT IgG MNT IgG
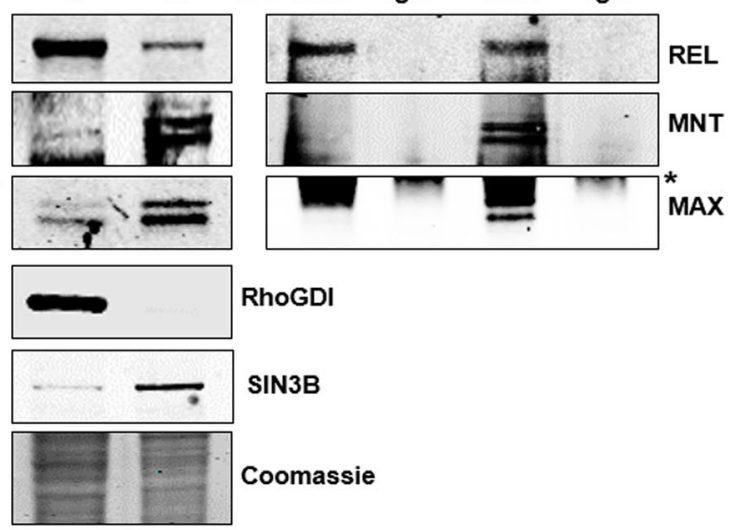

Fig. 3 (See legend on next page.) 
(see figure on previous page)

Fig. 3 MNT interacts with REL through its C-terminal region in the cytoplasm and the nucleus. a Co-immunoprecipitation assays with antiMNT and anti-p65 antibodies (the IgG as a negative control) in URMT and URMax34 after $\mathrm{Zn}^{2+}$ treatment. The inputs are shown in the left panel. b Co-immunoprecipitation assay with MNT antibodies (MNT $T^{50}$, an antibody against the 50 first amino acids of MNT protein; MNT ${ }^{582}$, an antibody against the 532-582 amino acids of MNT protein), and with p65 and p105/p50 antibodies, and lgG as a negative control. Two immunoblots for REL are shown (low and high intensity). $\mathbf{c}$ Working hypothesis with two options: MNT bound to REL homodimers, MNT bound to REL and other yet unknown protein(s). d Schematic representation of the mouse MNT deletion constructs used for the co-IP assays, $\triangle \mathrm{bHLH}$ and $\triangle \mathrm{Ct} 1 \mathrm{MNT}-\mathrm{HA}$. The dotted red lines connect the domains of MNT and REL necessary for the interaction. e C6 cell lysates $48 \mathrm{~h}$ after transfection with REL-flag (mouse) and $\triangle \mathrm{bHLH}$ or $\triangle \mathrm{Ct} 1 \mathrm{MNT}-\mathrm{HA}$ (mouse) were immunoprecipitated with anti-HA antibodies (lgG as negative control). The immunoblot of HA and REL is shown. The asterisk marks the heavy lgG band. $\mathbf{f}$ C6 cells were lysed following the nucleus/cytoplasm fractionation protocol, both in basal conditions or $30 \mathrm{~min}$ after treatment with TNFa $(100 \mathrm{ng} / \mathrm{mL})$ and immunoprecipitated with an anti-MNT antibody or the $\operatorname{lgG}$ (the latter as a negative control). The presence of REL, MNT, and MAX was determined in the immunoprecipitates by immunoblot. RhoGDI and SIN3B were analyzed as cytoplasm and nucleus markers, respectively. Coomassie blue was used as a protein loading control for the inputs. The asterisk marks the light lgG band.

(shScrambled) (Fig. 4b, left). This was confirmed by densitometry (Fig. 4b, right). We also analyzed the protein levels of MNT and NF- $\mathrm{kB}$ proteins after MNT knockdown. The results showed an increase in p65 and a decrease of REL and p50 protein levels when MNT levels were reduced (Fig. 4c).

Since REL was being translocated to the nucleus upon $M N T$ knockdown, we monitored the activation of the NF- $\mathrm{kB}$ pathway by luciferase assays with a synthetic construct carrying $5 \mathrm{kB}$ binding sites (pNF- $\mathrm{kB}-\mathrm{Luc}$ ). This is a well-established method to measure NF- $\mathrm{kB}$ transcriptional activity ${ }^{30}$. The luciferase activity significantly increased upon MNT knockdown both in LoVo and UR61 cells (Fig. 4d). Our previous work showed that MNT can act not only as MNT-MAX dimers but also as MNT homodimers ${ }^{4}$. To study whether MNT acts in concert with MAX to repress IKB $\alpha$ promoter, we tested the luciferase activity of the pNF-кB-Luc reporter in URMax34 cells, a UR61 derivative in which MAX can be induced by $\mathrm{Zn}^{2+}{ }^{4}$. In this model, MNT knockdown showed a similar elevation of promoter activity in the absence or presence of MAX (Fig. 4d). MNT knockdown and MAX induction were confirmed by immunoblot (Supplementary Fig. S3a).

Depletion of MNT results in decreased UR61 cell proliferation cells as described ${ }^{4}$ and in LoVo cells (Fig. 4e). In view of the MNT-REL interaction, we asked whether this effect of MNT was dependent on REL. Conversely to the depletion of MNT, depletion of REL in UR61 and LoVo cells did not result in a significant decrease in cell proliferation. However, the concomitant depletion of REL rescued the proliferation inhibition by MNT (Fig. 4e). These results suggest that the inhibition of proliferation upon MNT knockdown is mediated by REL. We confirmed MNT and REL knockdowns by immunoblot (Supplementary Fig. S3b).

\section{MNT directly regulates NFKBIA/IKBa}

We tested the expression of four NF-kB target genes (BCL-XL/BCL2L1, CCL5, IL6, IL8) upon MNT knockdown (Fig. 5a, upper panel) and MNT overexpression
(Fig. 4e, lower panel). The results confirmed the repressor effect of MNT on the NF-kB pathway.

Given the effects of MNT on the levels of proteins of the NF- $k B$ pathway (Fig. 4c), we asked whether this effect was exerted at the transcriptional level. LoVo cells were transfected with an MNT expression vector to analyze the mRNA levels. The results showed repression of RELA and NFKBIA after MNT overexpression while REL and $N F K B 1$ expression did not change (Fig. 5b). We focused on NFKBIA (IKB $\alpha)$, a repressor of the pathway that is induced by $\mathrm{REL}^{22,31}$. To confirm the regulation of NFKBIA/ $\mathrm{kB} \alpha$ by MNT, we compared NFKBIA mRNA levels after overexpressing either wild-type, $\triangle \mathrm{bHLH}$ (no binding to DNA) or $\triangle \mathrm{Ct} 1 \mathrm{MNT}$ (unable to interact with $\mathrm{REL})$. The results showed that the repression of NFKBIA was not detected with either of the deletion mutants (Fig. 5c). The results suggested a possible regulation of NFKBIA by an MNT-REL complex at the transcriptional level. Thus, we studied whether MNT was able to repress I $\mathrm{B} \alpha$ through reporter-luciferase assays. Using a construct carrying the promoter of NFKBIA (IKB $\alpha$-Luc), we found that increased MNT levels led to a repression of NFKBIA promoter activity. Consistently with this result, the depletion of MNT through shMNT constructs led to the activation of the NFKBIA promoter (Fig. $5 \mathrm{~d}$ ).

To test whether MNT was bound to the IкB $\alpha$ promoter, we analyzed the ChIP-seq data from the ENCODE consortium in the K562 cell line. We observed two coincident peaks of MNT, MYC, and MAX on the NFKBIA gene, suggesting bona fide binding sites for dimers of the MYCMAX-MNT protein family. The transcriptional repressor and MNT partner SIN3A also bound NFKBIA/ $\mathrm{\kappa} \mathrm{B} \alpha$ (Fig. 6a). MNT and REL ChIP experiments were performed in LoVo cells, which show constitutive NF-kB activation $^{32}$. We analyzed regions of the NFKBIA gene $-1000 \mathrm{bp}$ to $+1000 \mathrm{bp}$ from the TSS, which include some conserved REL-binding sites (Fig. 6b). The results showed MNT and REL binding to the NFKBIA gene (Fig. 6c). Interestingly, both MNT and REL had a maximum binding at $+171 /+343 \mathrm{bp}$, in the first exon of NFKBIA. To analyze whether both MNT and REL were bound as a 


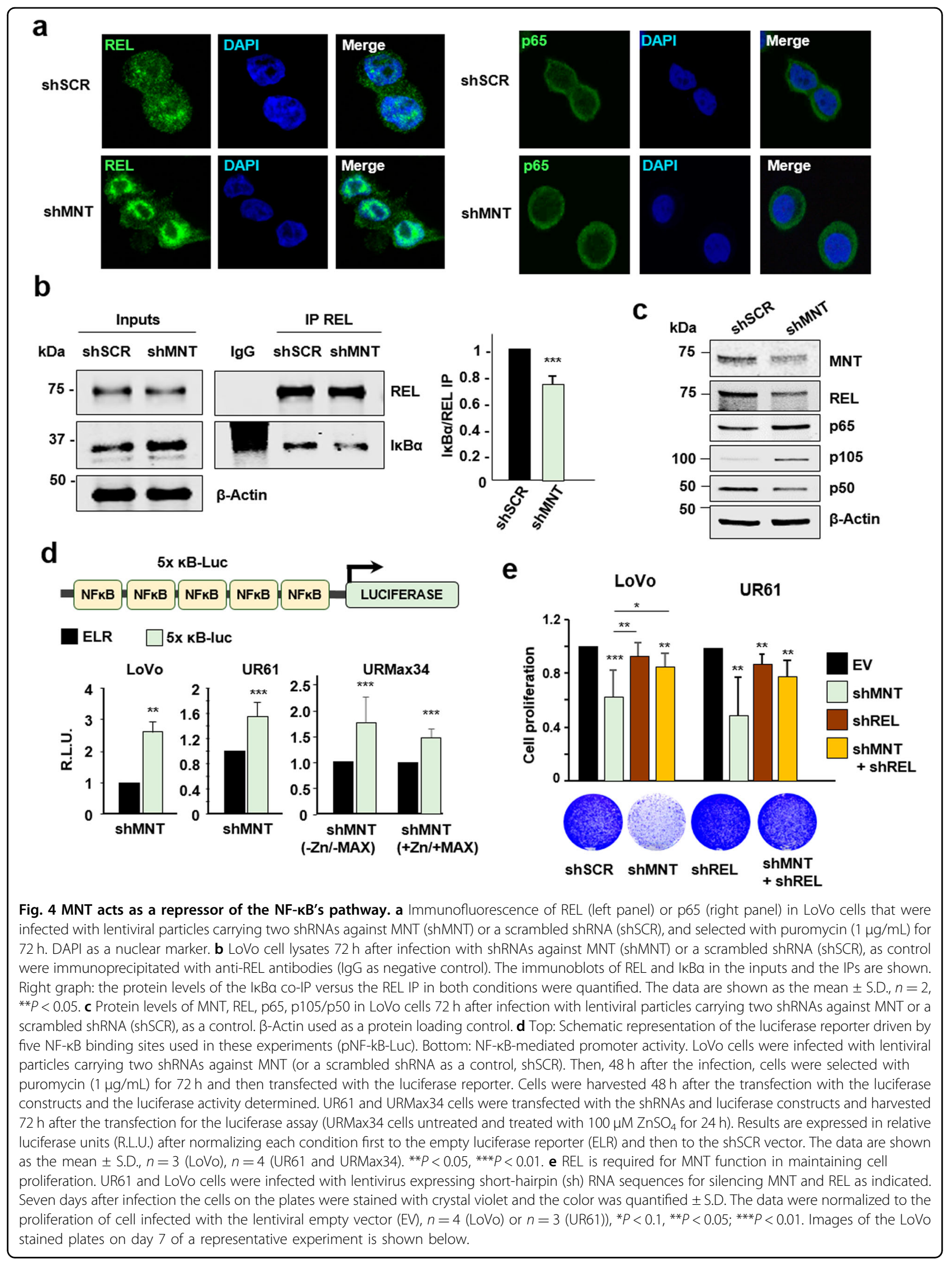




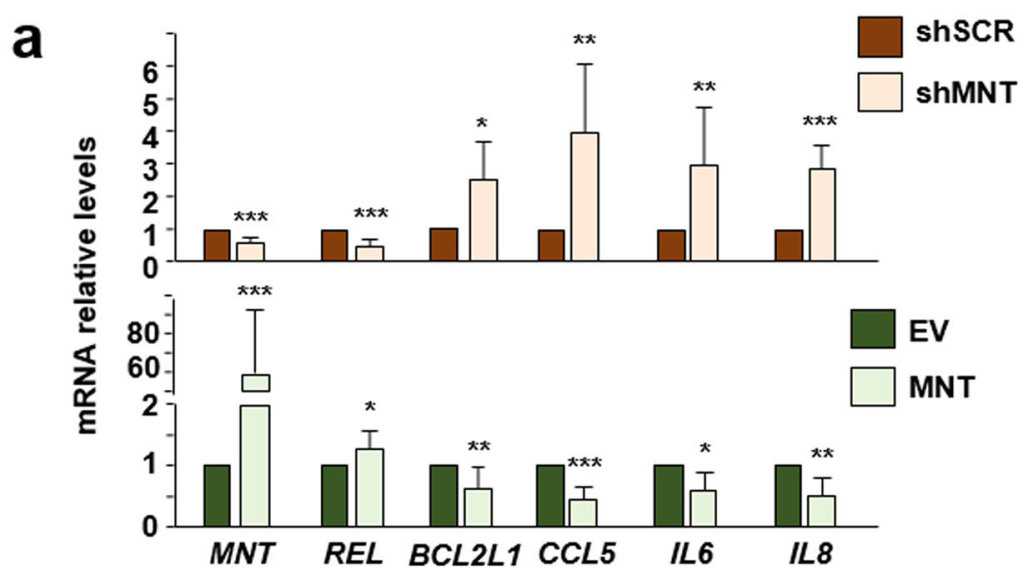

b

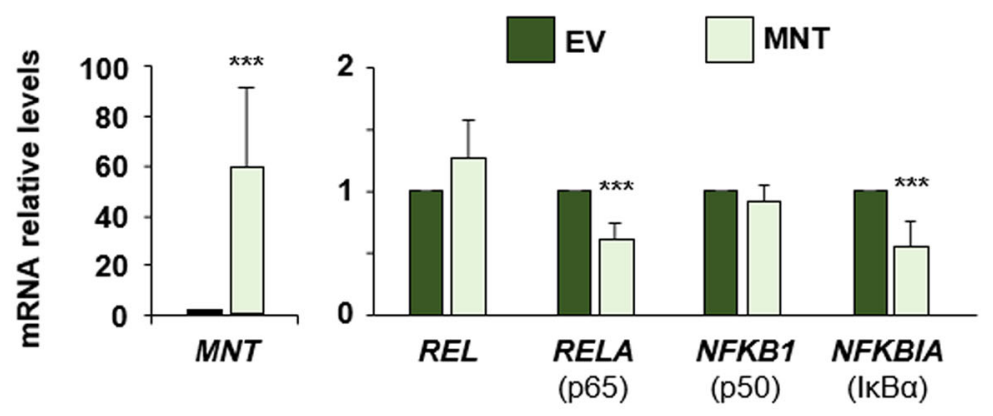

C
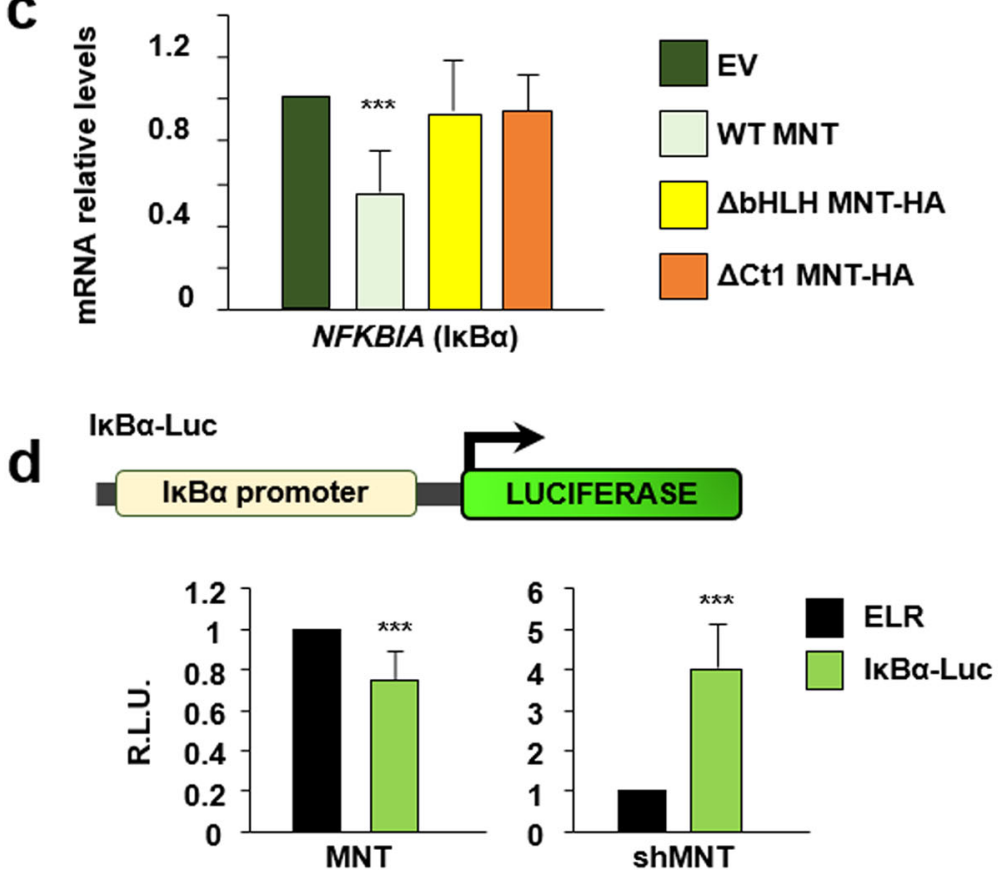

Fig. 5 (See legend on next page.) 
(see figure on previous page)

Fig. 5 MNT directly regulates NFKBIA (IKBa). a mRNA levels of MNT, REL, CCL5, IL6, IL8, BCL2L1 (BCL-XL) in LoVo cells $72 \mathrm{~h}$ after infection with shRNAs against MNT (shMNT) or a scrambled shRNA (shSCR) (upper panel) or $48 \mathrm{~h}$ after transfection with an MNT overexpressing construct or it's corresponding empty vector (EV) (lower panel) relative to RPS14 expression. The data are shown as the mean \pm S.D., $n \geq 3,{ }^{*} P<0.1,{ }^{* *} P<0.05$; ${ }^{* * *} P<$ 0.01. b mRNA levels of MNT, REL, RELA, NFKB1, NFKBIA in LoVo cells $48 \mathrm{~h}$ after transfection with an MNT overexpressing construct or it's corresponding empty vector (EV) relative to RPS14 expression. The data are shown as the mean \pm S.D., $n=4,{ }^{* *} P<0.05 ;{ }^{* * *} P<0.01$. c mRNA levels of NFKBIA in LoVo cells $48 \mathrm{~h}$ after transfection with a WT MNT, $\triangle \mathrm{bHLH}$, or $\triangle \mathrm{Ct} 1 \mathrm{MNT}-\mathrm{HA}$ overexpressing construct, or their corresponding empty vector (EV) relative to RPS14 expression. The data are shown as the mean \pm S.D., $n=6$ (WT), $n=3$ (mutants) ${ }^{* * *} P<0.01$. $\mathbf{d}$ Top: Schematic representation of the luciferase reporter driven by the human NFKBIA (IKBa) promoter (IKBa-Luc) used in this work. For the luciferase assay overexpressing MNT, the luciferase activity was measured $48 \mathrm{~h}$ after transfection with the luciferase vectors and MNT expression vector or their corresponding empty vectors (on the left). For the luciferase assay after MNT knockdown, cells were first infected with lentiviral particles carrying two shRNAs against MNT (or a scrambled shRNA as a control, shSCR), selected with puromycin $(1 \mu \mathrm{g} / \mathrm{mL})$ for $72 \mathrm{~h}$ and then transfected with the luciferase vectors (on the right). Results are expressed in relative luciferase units (R.L.U.) after normalizing each condition first to the luciferase empty reporter (ELR) and then to the empty vector of MNT (pCMVSport6) (left) or the shSCR (right). The data are shown as the mean \pm S.D., $n=3$ (shMNT), $n=4$ (MNT), ${ }^{* * *} P<0.01$.

complex, we carried out a re-ChIP experiment. For this, we first immunoprecipitated chromatin with anti-MNT, and then, MNT-bound chromatin was immunoprecipitated with anti-REL antibodies. The results showed binding of MNT-REL to the $+171 /+343$ region. As a positive control, REL $\rightarrow$ p50 re-ChIP gave a positive signal on $-67 /-316$, a predicted REL-binding site in that region (Fig. 6d).

Altogether, the data suggest that MNT inhibits the NF$\kappa B$ pathway by retaining REL dimers in the cytoplasm and by repressing genes normally activated by REL in the nucleus. When MNT levels drop, the NF- $\kappa B$ pathway is activated, as REL dimers are released and they induce the transcription of several NF- $\mathrm{kB}$ target genes (Fig. 6e).

\section{Discussion}

Here we report evidence of the involvement of MNT in the regulation of one of the most important signaling pathways: the NF-KB pathway. First, MNT and REL interact in some mouse, rat, and human cell lines, and this complex can be found in both cytoplasm and nucleus. Second, MNT knockdown triggers REL (but not p65) translocation into the nucleus and the NF- $\mathrm{KB}$ pathway activation. MNT knockdown also impairs cell proliferation in a REL-dependent manner. Third, MNT-REL complex binds to and regulates a crucial NF- $\mathrm{B}$ target gene: NFKBIA/IKB $\alpha$. Interestingly, MNT and REL interaction is independent of MAX, as it also takes place in MAX-deficient cells and REL was not found in MAX immunoprecipitates. The fact that we did not detect MNT-REL interaction in all the cell lines tested indicates that the interaction may depend on another ancillary protein which expression may vary among cell types. This would affect the efficiency of the co-immunoprecipitation and the proximity ligation assays, leading to a more difficult detection of MNT and REL interaction. Although REL forms heterodimers with $\mathrm{p} 65$ or $\mathrm{p} 50^{22}$, we did not detect any of them bound to MNT, which suggests that MNT binds specifically to REL. The C-terminal region of
MNT, which is rich in prolines, was necessary for the interaction with $\mathrm{REL}^{2}$. These proline-rich regions are usually involved in protein-protein interactions ${ }^{33}$. This agrees with the result showing that REL is found in MNT immunoprecipitates when using an antibody recognizing the first 50 amino acids of MNT but not when using an antibody recognizing the C-terminal domain of MNT. This result can be explained because the binding of the antibody against the MNT C-terminal domain may disrupt the MNT-REL interaction. We also demonstrated that REL Inhibitory Domain (RID) is needed for the formation of MNT-REL complexes. In addition, we showed that the MNT-REL complex is found in the cytoplasm under basal conditions but also in the nucleus after TNF $\alpha$ stimulation, suggesting a transcriptional function of the complex.

$M N T$ knockdown provoked the dissociation of the RELIK $B \alpha$ complexes and the translocation of REL to the nucleus, commonly observed when the NF- $\kappa B$ pathway is activated $^{34}$. In fact, we demonstrate the activation of the NF- $\mathrm{kB}$ pathway upon MNT silencing, as assessed by a luciferase NF- $\kappa B$ responsive reporter and the increased expression of several NF- $\mathrm{KB}$ target genes. In accordance with this result, some NF- $\mathrm{KB}$ target genes were downregulated after $M N T$ overexpression. Thus, MNT might be acting as a limiter of NF- $\mathrm{KB}$ activity in the absence of specific activators of the pathway. We also show that MNT regulates the NF- $\mathrm{B}$ pathway independently of MAX. We have previously published MAX-independent functions of MNT ${ }^{4}$. This novel MNT function supports our idea that MNT has functions beyond its partner MAX, not explored before.

NFKBIA encodes ІкB $\alpha$, which binds to and retains the NF- $\mathrm{KB}$ members in the cytoplasm under the absence of stimulatory signals ${ }^{34}$. Once a stimulus is detected by the cell, the NF- $\kappa B$ pathway is activated and ІкB $\alpha$ degraded. However, NF- $\kappa B$ also induces a negative feedback loop, leading to the transcription of NFKBIA/IKB $\alpha$. The newly synthesized I $\mathrm{B} \alpha \alpha$ enters the nucleus and shuttles NF- $\kappa B$ 
a

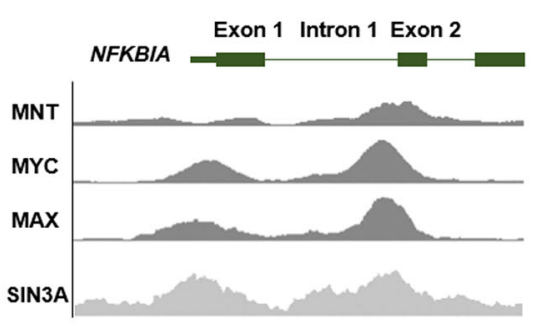

C

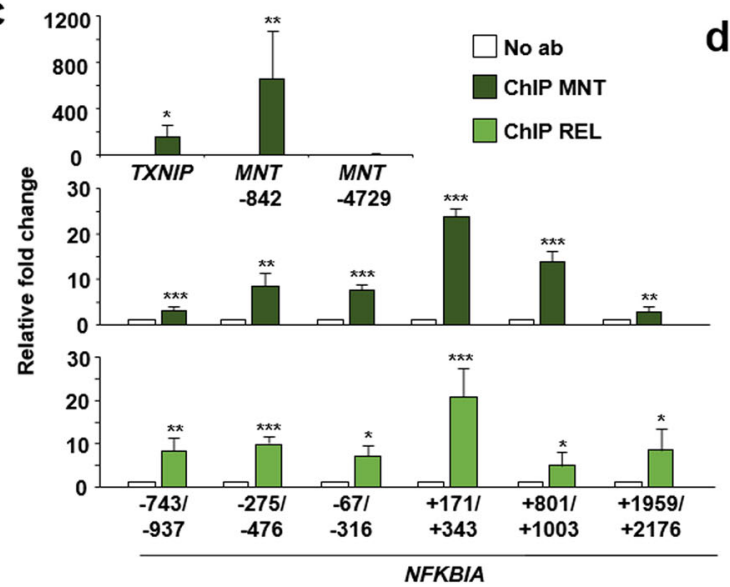

b

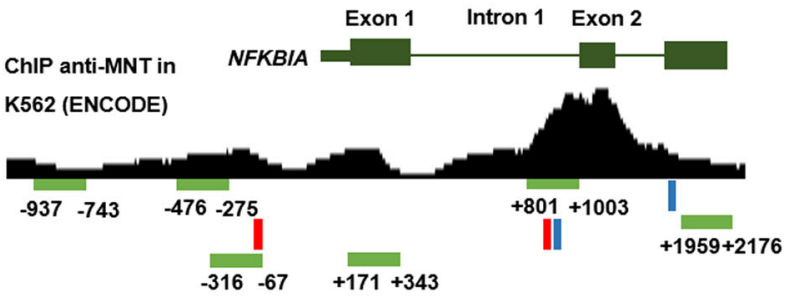

d

e
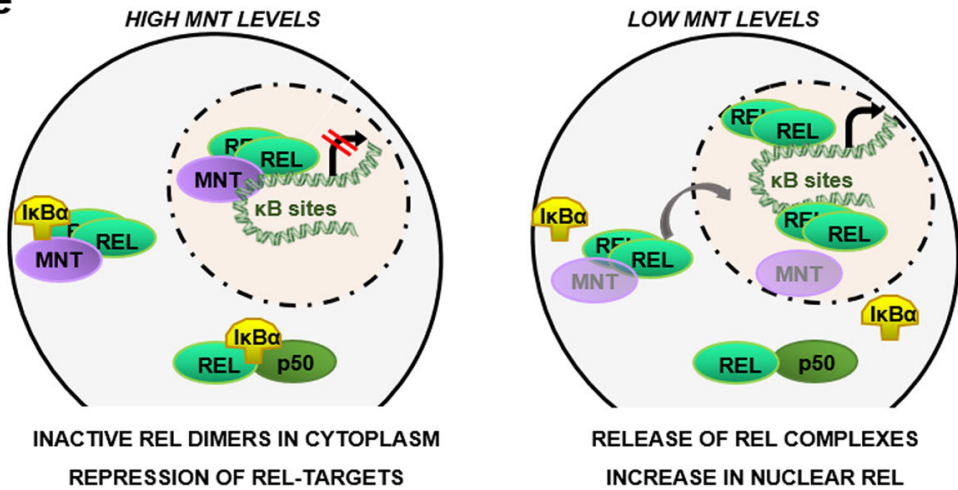

RELEASE OF REL COMPLEXES

INCREASE IN NUCLEAR REL

ACTIVATION OF THE NF-KB PATHWAY

Fig. 6 MNT and REL regulate NFKBIA. a Schematic representation of human NFKBIA (IKBa) gene showing the peaks for MNT, MYC, MAX (K562 cell line), and SIN3A (GM78), as published by the ENCODE project consortium (genome-euro.ucsc.edu/). b Schematic representation of human NFKBIA ( $\mid \mathrm{KBa})$ gene showing the peaks for MNT binding in the K562 cell line, together with the amplicons analyzed below by ChIP-PCR. The conserved RELbinding sites obtained in the ENCODE project using the TFBS Conserved (tfbsConsSites) track are marked in red rectangles. The E-boxes found in NFKBIA are marked in blue (CACGCG at +907 bp and CACGTG at +1899 bp). c ChIP of MNT (upper panel) or REL (lower panel) in LoVo cells on NFKBIA promoter. TXNIP and MNT - 842 used as positive controls and a region upstream MNT promoter (MNT -4729), as a negative control for MNT ChIP. The data are shown as the mean \pm S.D., $n=3,{ }^{* *} P<0.05 ;{ }^{* *} P<0.01$. d Re-ChIP of MNT with REL (MNT $\rightarrow$ REL) and REL with p50 (REL $\rightarrow$ p50) in LoVo cells. MNT and REL ChIPs were also re-immunoprecipitated with IgG as a negative control of the technique. The data are shown as the mean \pm S.D., $n \geq 3$, ${ }^{*} P<0.1$. e Model of the MNT regulation of NF-KB signaling. Our results indicate that in a high MNT-levels condition, MNT would be possibly regulating NF-KB signaling by retaining REL dimers in the cytoplasm and by forming a complex with REL in the nucleus that would repress the genes that are normally activated by REL dimers. When we silence MNT, REL dimers are released and they translocate into the nucleus, with the consequent increase in NF-KB target genes and the activation of the pathway.

dimers back to the cytoplasm to terminate transcrip-

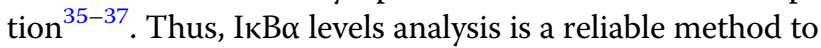
study the transcriptional activity of NF- $\mathrm{KB}^{38}$. ChIP assays show the binding of MNT and REL to the first exon of the
IкB $\alpha$ gene and re-ChIP experiments confirm that MNT and REL bind together to that same region. MNT and other MXD proteins exert a transcriptional repressive effect in many genes due to the interaction with SIN3 
co-repressor ${ }^{1,39}$. The ENCODE data shows SIN3A binding to the $N F K B I A / \kappa \mathrm{B} \alpha$ gene, which can explain the transcriptional repression of the gene. The fact that MNT can bind and repress IкB $\alpha$ at least in some cell types, opens a new level of regulation of the NF- $k B$ pathway, i.e., the MNT-REL mediated repression of genes otherwise activated by REL.

MNT pro-survival role has been described in several models, although the exact mechanism responsible for that remains unknown ${ }^{9,40,41}$. Here we describe the unexpected discovery of an interaction between MNT and REL, an NF-kB pathway component, which has a key role in regulating cell homeostasis. It can be hypothesized that MNT would impair REL function by retaining REL dimers in the cytoplasm and also by repressing REL-target genes (Fig. 6e). Thus, the previously described effects of MNT on proliferation could be in part exerted through the regulation of NF-KB activity. Indeed, we have shown that REL depletion abrogates the antiproliferative effect of MNT depletion in at least two cell lines. This suggests that the pro-survival activity of MNT is mediated at least in part through REL. Moreover, it has been described that REL induces MYC expression ${ }^{42-45}$. Considering the MYC-MNT antagonism, it would be possible that MNT would control MYC levels through the inhibition of REL functions. Furthermore, loss of MNT in T-cells leads to a disruption of $\mathrm{T}$-cell development and lymphomagenesis $^{40,41}$. As REL is also important for Th1 cell differentiation $^{46}$, it is possible that the effects of MNT on the immune system are related to its interaction with REL

In summary, our results show unprecedented evidence of an MNT-REL interaction, which links the MYC-MNT with the NF-kB pathways and opens a new path to the understanding of MNT's wide functions in cell biology.

\section{Materials and methods}

\section{Cell culture, transfections, and lentiviral transduction}

Cell lines were obtained from ATCC and grown in either RPMI-1640 or DMEM (Corning) supplemented with $10 \%$ fetal bovine serum (Gibco, ThermoFisher Scientific, Waltham, MA, USA), $150 \mu \mathrm{g} / \mathrm{mL}$ of gentamicin, and $2 \mu \mathrm{g} / \mathrm{mL}$ of ciprofloxacin. All cells tested negative for Mycoplasma infection by PCR. UR61 derivate from PC12 cells $^{47}$. URMax34 cell line derives from UR61 and expresses a MAX gene inducible by $\mathrm{ZnSO}_{4}(100 \mu \mathrm{M}$ $\mathrm{ZnSO}_{4}$ for $\left.24 \mathrm{~h}\right)^{4}$, LoVo cells were transfected with ScreenFect A reagent (Screenfect, Eggenstein-Leopoldshafen, Germany), following the manufacture's indications and using the reagent at $3 \times \mu \mathrm{g}$ DNA. C6 were transfected with polyethyleneimine reagent (PEI, Polysciences, Warrington, PA, USA), using $2.5 \mu \mathrm{g}$ of PEI per $\mu \mathrm{g}$ of DNA. UR61 and URMax34 cells were transfected using the Ingenio Electroporation solution (Mirus) in an Amaxa nucleofector. Transfected plasmids were human
MNT (pCMVSport6-MNT, Origene Technologies, Rockville, MD, USA); mouse WT MNT-HA, $\triangle \mathrm{bHLH}$ MNT-HA (murine MNT carrying a deletion of amino acids 221-272), $\Delta$ Ct1 MNT-HA (murine MNT carrying a deletion of 276 amino acids in the C-terminal region and tagged with HA), $\triangle \mathrm{Nt} 1 \mathrm{MNT}-\mathrm{HA}$ (murine MNT carrying a deletion of amino acids 1-300), and $\Delta \mathrm{Nt} 2 \mathrm{MNT}-\mathrm{HA}$ (murine MNT carrying a deletion of amino acids 1-271). MNT deletion constructs were made from the pcDNA3.1 WT MNT-HA ${ }^{48}$. This plasmid contains the mouse MNT sequence together with a hemagglutinin (HA) tag at its Cterminal domain. By designing different primers we generated the fragments corresponding to $\Delta \mathrm{Ct} 1, \Delta \mathrm{Nt} 1$, and $\Delta \mathrm{Nt} 2$ constructs, which were inserted into the BamHI and EcoRI sites of the pcDNA3, carrying a zeocin resistance gene and an HA tag.

As for REL plasmids, we used mouse c-Rel cFlag pcDNA3 (gift from Stephen Smale, RRID: Addgene_20013, http://n2t.net/addgene:20013); human pcDNA-FLAG-REL (RRID:Addgene_27253, http://n2t. net/addgene:27253 ${ }^{49}$ and human pcDNA-FLAGRELARID with a deletion of 323-422 amino acids (Addgene \# 27265; http://n2t.net/addgene:27265; RRID: Addgene_27265) ${ }^{28}$ (both gifts from Thomas Gilmore). Lentiviral production was performed as previously $\operatorname{described}^{50}$, and polybrene at $3 \mu \mathrm{g} / \mathrm{mL}$ was used to increase the infection efficiency. Lentiviral particles carried a scrambled short-hairpin RNA as a control, shSCR (SHC016-1EA) or two short-hairpin RNAs against MNT human gene, shMNT (TCR0000234788 and TRCN0000235815), shREL (human TRCN0000435698 and mouse TRCN0000042551) from Sigma-Aldrich, St. Louis, MO, USA. Activation of the NF-kB's pathway was achieved by TNF $\alpha$ (Peprotech, Rocky Hill, CT, USA) stimulation for $30 \mathrm{~min}$ at $25-100 \mathrm{ng} / \mathrm{mL}$.

\section{RNA extraction and expression analysis}

For qPCR, total RNA was isolated using the TRI Reagent ${ }^{\circledR}$ Solution (Invitrogen, ThermoFisher Scientific, Waltham, MA, USA). The cDNA was generated by reverse transcription (RT) using the iScript (Bio-Rad, Hercules, CA, USA). Quantitative polymerase chain reaction (qPCR) was performed with specific primers (Supplementary Table 2) using the $\mathrm{iTaq}^{\mathrm{TM}}$ Universal SYBR ${ }^{\circledR}$ Green Supermix (Bio-Rad) and CFX ConnectTM Real-Time PCR Detection System (Bio-Rad). RNA was converted into cDNA and analyzed as described ${ }^{51}$. Levels of mRNA were normalized against RPS14 (ribosomal protein S14) mRNA levels.

\section{Immunoprecipitation assays and immunoblot}

For the immunoprecipitation assays, lysates were obtained using the $1 \%$ NP-40 IP lysis buffer $(50 \mathrm{mM}$ Tris$\mathrm{HCl} \mathrm{pH}$ 7.5, $150 \mathrm{mM} \mathrm{NaCl}, 1 \%$ NP-40, 1 mM EDTA pH 8, 
$0.5 \mathrm{mM}$ EGTA $\mathrm{pH} 8$, and protease and phosphatase inhibitors). For MNT-REL co-IP in LoVo cells, the cells were lysed instead with a mild hypotonic buffer $(10 \mathrm{mM}$ HEPES pH 7, $10 \mathrm{mM} \mathrm{KCl,} 0.25 \mathrm{mM}$ EDTA pH 8, $0.125 \mathrm{mM}$ EGTA pH 8, $0.5 \mathrm{mM}$ spermidine, 0.1\% NP-40, $1 \mathrm{mM}$ DTT and phosphatase and protease inhibitors). Total cell lysis, immunoblots, and immunoprecipitations (IPs) were performed as described ${ }^{51}$. The antibodies are shown in Supplementary Table 3.

\section{Preparation of cytoplasmic and nuclear fractions}

Cytoplasmic extracts were obtained by a $30 \mathrm{~min}$ lysis with a hypotonic buffer $(10 \mathrm{mM}$ HEPES $\mathrm{pH} 7,10 \mathrm{mM}$ $\mathrm{KCl}, 0.25 \mathrm{mM}$ EDTA pH 8, $0.125 \mathrm{mM}$ EGTA pH 8, $0.5 \mathrm{mM}$ spermidine, $0.1 \% \mathrm{NP}-40,1 \mathrm{mM}$ DTT, and phosphatase and protease inhibitors). Nuclear extracts were obtained after a $5 \mathrm{~min}$ centrifugation at $1500 \mathrm{rpm}$ and lysed with $1 \%$ NP-40 IP lysis buffer $(50 \mathrm{mM}$ Tris- $\mathrm{HCl} \mathrm{pH}$ 7.5, $150 \mathrm{mM} \mathrm{NaCl}, 1 \%$ NP-40, $1 \mathrm{mM}$ EDTA pH 8, $0.5 \mathrm{mM}$ EGTA pH 8, and protease and phosphatase inhibitors). Once the lysates were obtained, the immunoprecipitation and immunoblots were performed as described ${ }^{51}$.

\section{Proteomic studies}

Protein immunoprecipitation was carried out as described in the protein immunoprecipitation section except for the elution, which was carried out according to the "On-beads digestion" protocol ${ }^{52}$. Briefly, beads-immunocomplexes were trypsinized, in order to digest the baits and the interacting proteins. After trypsinization, protein samples were purified and finally resuspended in $0.1 \%$ (v:v) trifluoroacetic acid buffer to be analyzed by mass spectrometry on a Q-Exactive mass spectrometer (ThermoFisher Scientific) connected to an Ultimate Ultra3000 chromatography system (ThermoFisher Scientific). Mass spectra were analyzed using the MaxQuant Software package of two technical replicates and biological triplicates of the experimental and control samples. Raw data files were searched against a Rattus norvegicus (Rat) database (Uniprot RAT), using a mass accuracy of $6 \mathrm{ppm}$ and 0.01 false discovery rate (FDR) at both peptide and protein level.

\section{Immunofluorescence staining}

Adherent cells grown on glass coverslips were fixed with $\%$ paraformaldehyde in PBS for $15 \mathrm{~min}$ at room temperature. Fixed cells were washed with PBS and permeabilized and blocked with $1 \%$ Triton X-100, 3\% BSA in PBS for $30 \mathrm{~min}$. Then, cells were treated with blocking buffer (3\% BSA; 0.1\% Triton X-100 in PBS) for 20 min, washed with PBS and $0.1 \%$ Triton X-100 in PBS, and incubated overnight at $4{ }^{\circ} \mathrm{C}$ with the primary antibodies 1:200 diluted in blocking buffer. The slides were incubated for $1 \mathrm{~h}$ at room temperature with the secondary antibody conjugated with FITC (Jackson Laboratories, Bar Harbor,
ME, USA). The samples were mounted with ProLong Gold Antifade mountant (ThermoFisher Scientific, Waltham, MA, USA). Confocal images were obtained with a Leica TCS SP5 microscope and processed and quantified using the ImageJ software (https://imagej.nih.gov/ij/ download.html). The antibodies used are described in Supplementary Table 3.

\section{In situ proximity ligation assay}

In situ proximity ligation assay (PLA) was performed with Duolink in situ Red Starter kit Mouse/Rabbit (SigmaAldrich, St. Louis, MO, USA) according to the manufacturer's instructions. In situ PLA-positive signals were quantified using the ImageJ software. Cell samples were visualized using a Zeiss Axio Imager M1 upright fluorescence microscope. The primary antibodies used are described in Supplementary Table 3.

\section{Proliferation assays}

LoVo or UR61 cells were transfected with the pLKO vector containing the shRNA sequences against MNT (mix of two shRNAs) or REL (human for LoVo and mouse/rat for UR61). After $48 \mathrm{~h}$, puromycin was added $(1 \mu \mathrm{g} / \mathrm{mL}$ for LoVo and $0.1 \mu \mathrm{g} / \mathrm{mL}$ for UR61), which was refreshed every 2-3 days. After 7 days of selection, cells were washed with $1 \times$ PBS, stained with a crystal violet solution (1\% acetic acid, $1 \%$ methanol, $1 \%$ crystal violet dye), and scanned. Finally, they were dissolved in a $10 \%$ acetic acid solution and their absorbance was measured at $620 \mathrm{~nm}$.

\section{Luciferase reporters and assays}

Cells were transfected with a mix of DNA constructs specific for each experiment. We used a Firefly sp. luciferase reporter gene regulated by five putative NF- $\mathrm{kB}$ regulatory elements, pNF-kB-Luc ${ }^{30}$ (Stratagene, La Jolla, $\mathrm{CA}$, a gift from Jose $\mathrm{P}$ Vaqué) and wild-type human IкB $\alpha$ promoter construct, which has been previously described $^{53}$. The firefly luciferase gene reporter vector carrying five NF- $\mathrm{kB}$ binding sites was described. As a control, we used a vector without any specific transcription regulatory sequence. The pRL-null Renilla plasmid (Promega, Madison, WI, USA) was also transfected. Luciferase reporter assays were carried out with the Dual-Luciferase Reporter (DLR) System (Promega), following the manufacturer's instructions. Luminescence from both luciferase reactions was measured with the Glomax Multi-detection System (Promega). Firefly luminescence values were normalized against Renilla luminescence values.

\section{Chromatin immunoprecipitation (ChIP and Re-ChIP) assays}

Total cell extracts were first lysed with a hypotonic buffer (described in the "Nuclear/cytoplasm fractionation" section) for purifying the nuclear compartment. Then, nuclear lysis and chromatin immunoprecipitation (ChIP) 
were performed essentially as described ${ }^{54}$. For the ReChIP experiments, we carried out an intermediary step of elution with elution buffer plus $10 \mathrm{mM}$ DTT, $1 \mathrm{~h}$ at $37^{\circ} \mathrm{C}$. The resulting DNA was incubated with the second antibody. Immunoprecipitated DNA was purified with the QIAquick PCR Purification Kit (Qiagen, Germantown, MD, USA) and analyzed by qPCR. The SYDH ENCODE project was used as a reference for primer designing on the human NFKBIA gene (http://genome.ucsc.edu/ ENCODE). The primers and antibodies used are described in Supplementary Tables 2 and 3, respectively.

\section{Statistical analysis}

Student's two-tail $t$-test was used to evaluate the significance of differences between control and experimental groups. A $P$-value was noted as ${ }^{*} P<0.1,{ }^{* *} P<$ $0.05,{ }^{* * * *} P<0.01$.

\section{Acknowledgements \\ The work was supported by grant SAF2017-88026-R from Agencia Estatal de Investigación, Spanish Government, to J.L. and M.D.D. J.L.-P. and M.C.L.-N. were recipients of F.P.U. fellowships and L.G.-G. of a F.P.I. fellowship from the Spanish Government. We are grateful to Jose P. Vaqué and Jose L. Fernandez-Luna for plasmids and antibodies, and Rosa Blanco, Victor Campa and Sandra Zunzunegui for technical help.}

\section{Author details}

${ }^{1}$ Departmento de Biología Molecular, Instituto de Biomedicina y Biotecnología de Cantabria (IBBTEC), CSIC-Universidad de Cantabria, Santander, Spain. ${ }^{2}$ Cancer Research Program, Institut Hospital del Mar d'Investigacions Mèdiques, CIBERONC, Hospital del Mar, Barcelona, Spain. ${ }^{3}$ Systems Biology Ireland, University College Dublin, Dublin, Ireland. ${ }^{4}$ Shriners Hospitals for Children Research Center, Department of Cell, Developmental and Cancer Biology and Department of Orthopaedics and Rehabilitation, Oregon Health and Science University, Portland, OR, USA. ${ }^{5}$ Present address: Department of Microbiology, Tumor and Cell Biology (MTC), Biomedicum B7, Karolinska Institutet, Stockholm, Sweden. ${ }^{6}$ Present address: Department of Cell Biology UT Southwestern Medical Center, Dallas, TX, USA. ${ }^{7}$ Present address: Edinburgh Cancer Research Center, Institute of Genetics and Molecular Medicine, University of Edinburgh, Edinburgh, UK. ${ }^{8}$ Present address: Dept. of Biochemistry, Universidade Federal de Santa Catarina (UFSC), Florianópolis, Brazil

\section{Conflict of interest}

The authors declare that they have no conflict of interest.

\section{Publisher's note}

Springer Nature remains neutral with regard to jurisdictional claims in published maps and institutional affiliations.

Supplementary Information accompanies this paper at (https://doi.org/ 10.1038/s41389-020-00298-4).

Received: 10 April 2020 Revised: 20 November 2020 Accepted: 2 December 2020

Published online: 08 January 2021

\section{References}

1. Hurlin, P. J., Queva, C. \& Eisenman, R. N. Mnt: a novel Max-interacting protein and Myc antagonist. Curr. Top. Microbiol. Immunol. 224, 115-121 (1997).

2. Meroni, G. et al. Rox, a novel bHLHZip protein expressed in quiescent cells that heterodimerizes with Max, binds a non-canonical $E$ box and acts as a transcriptional repressor. EMBO J. 16, 2892-2906 (1997).
3. Meroni, G. et al. Mlx, a new Max-like bHLHZip family member: the center stage of a novel transcription factors regulatory pathway? Oncogene 19, 3266-3277 (2000).

4. Lafita-Navarro, M. C. et al. The MNT transcription factor autoregulates its expression and supports proliferation in MYC-associated factor X (MAX)deficient cells. J. Biol. Chem. 295, 2001-2017 (2020).

5. Conacci-Sorrell, M., McFerrin, L. \& Eisenman, R. N. An overview of MYC and its interactome. Cold Spring Harb. Perspect. Med. 4, 1-24 (2014).

6. Grzenda, A., Lomberk, G., Zhang, J. S. \& Urrutia, R. Sin3: master scaffold and transcriptional corepressor. Biochim Biophys. Acta 1789, 443-450 (2009).

7. Yang, G. \& Hurlin, P. J. MNT and emerging concepts of MNT-MYC antagonism. Genes 8, 83 (2017).

8. Link, J. M. \& Hurlin, P. J. The activities of MYC, MNT and the MAX-interactome in lymphocyte proliferation and oncogenesis. Biochim. Biophys. Acta 1849, 554-562 (2015).

9. Hurlin, P. J. et al. Deletion of Mnt leads to disrupted cell cycle control and tumorigenesis. EMBO J. 22, 4584-4596 (2003).

10. Toyo-oka, K. et al. Loss of the Max-interacting protein Mnt in mice results in decreased viability, defective embryonic growth and craniofacial defects: relevance to Miller-Dieker syndrome. Hum. Mol. Genet. 13 1057-1067 (2004).

11. Foley, K. P. et al. Targeted disruption of the MYC antagonist MAD1 inhibits cell cycle exit during granulocyte differentiation. EMBO J. 17, 774-785 (1998).

12. Queva, C., McArthur, G. A., Iritani, B. M. \& Eisenman, R. N. Targeted deletion of the S-phase-specific Myc antagonist Mad3 sensitizes neuronal and lymphoid cells to radiation-induced apoptosis. Mol. Cell Biol. 21, 703-712 (2001).

13. Cvekl, A. Jr., Zavadil, J., Birshtein, B. K., Grotzer, M. A. \& Cvekl, A. Analysis of transcripts from 17p13.3 in medulloblastoma suggests ROX/MNT as a potential tumour suppressor gene. Eur. J. Cancer 40, 2525-2532 (2004).

14. Edelmann, J. et al. High-resolution genomic profiling of chronic lymphocytic leukemia reveals new recurrent genomic alterations. Blood 120, 4783-4794 (2012).

15. Lo Nigro, C. et al. The human ROX gene: genomic structure and mutation analysis in human breast tumors. Genomics 49, 275-282 (1998).

16. Vermeer, M. H. et al. Novel and highly recurrent chromosomal alterations in Sezary syndrome. Cancer Res. 68, 2689-2698 (2008).

17. Schaub, F. X. et al. Pan-cancer alterations of the MYC oncogene and its proximal network across the cancer genome atlas. Cell Syst. 6, 282-300.e2 (2018).

18. Nguyen, H. V. et al. Development and survival of MYC-driven lymphomas require the MYC antagonist MNT to curb MYC-induced apoptosis. Blood 135 1019-1031 (2020).

19. Romero, O. A. et al. MAX inactivation in small cell lung cancer disrupts MYC SWI/SNF programs and is synthetic lethal with BRG1. Cancer Discov. 4, 292-303 (2014).

20. Burnichon, N. et al. MAX mutations cause hereditary and sporadic pheochromocytoma and paraganglioma. Clin. Cancer Res. 18, 2828-2837 (2012).

21. Pantaleo, M. A. et al. Genome-wide analysis identifies MEN1 and MAX mutations and a neuroendocrine-like molecular heterogeneity in quadruple WT GIST. Mol. Cancer Res. 15, 553-562 (2017).

22. Gilmore, T. D. \& Gerondakis, S. The c-Rel transcription factor in development and disease. Genes Cancer 2, 695-711 (2011).

23. Zhang, Q., Lenardo, M. J. \& Baltimore, D. 30 Years of NF-kappaB: a blossoming of relevance to human pathobiology. Cell 168, 37-57 (2017).

24. Chen, I. S., Wilhelmsen, K. C. \& Temin, H. M. Structure and expression of c-rel, the cellular homolog to the oncogene of reticuloendotheliosis virus strain T. J. Virol. 45, 104-113 (1983).

25. Gilmore, T. D., Cormier, C., Jean-Jacques, J. \& Gapuzan, M. E. Malignant transformation of primary chicken spleen cells by human transcription factor c-Rel. Oncogene 20, 7098-7103 (2001).

26. Hunter, J. E., Leslie, J. \& Perkins, N. D. c-Rel and its many roles in cancer: an old story with new twists. Br. J. Cancer 114, 1-6 (2016).

27. Hopewell, R. \& Ziff, E. B. The nerve growth factor-responsive PC12 cell line does not express the Myc dimerization partner Max. Mol. Cell Biol. 15, 3470-3478 (1995)

28. Leeman, J. R., Weniger, M. A., Barth, T. F. \& Gilmore, T. D. Deletion analysis and alternative splicing define a transactivation inhibitory domain in human oncoprotein REL. Oncogene 27, 6770-6781 (2008).

29. Pimentel-Muinos, F. X., Mazana, J. \& Fresno, M. Biphasic control of nuclear factor-kappa B activation by the $T$ cell receptor complex: role of tumor necrosis factor alpha. Eur. J. Immunol. 25, 179-186 (1995). 
30. Martin, D., Galisteo, R., Ji, Y., Montaner, S. \& Gutkind, J. S. An NF-kappaB gene expression signature contributes to Kaposi's sarcoma virus vGPCR-induced direct and paracrine neoplasia. Oncogene 27, 1844-1852 (2008).

31. Chen, C., Edelstein, L. C. \& Gelinas, C. The Rel/NF-kappaB family directly activates expression of the apoptosis inhibitor $\mathrm{BCl}-\mathrm{x}(\mathrm{L})$. Mol. Cell Biol. 20, 2687-2695 (2000).

32. Sakamoto, K. et al. Constitutive NF-kappaB activation in colorectal carcinoma plays a key role in angiogenesis, promoting tumor growth. Clin. Cancer Res. 15 2248-2258 (2009).

33. Kay, B. K. Williamson, M. P. \& Sudol, M. The importance of being proline: the interaction of proline-rich motifs in signaling proteins with their cognate domains. FASEB J. 14, 231-241 (2000).

34. Gilmore, T. D. Introduction to NF-kappaB: players, pathways, perspectives. Oncogene 25, 6680-6684 (2006).

35. Hayden, M. S. \& Ghosh, S. Shared principles in NF-kappaB signaling. Cell 132 344-362 (2008).

36. Kanarek, N. \& Ben-Neriah, Y. Regulation of NF-kappaB by ubiquitination and degradation of the IkappaBs. Immunol. Rev. 246, 77-94 (2012).

37. Sun, S. C., Ganchi, P. A., Ballard, D. W. \& Greene, W. C. NF-kappa B controls expression of inhibitor I kappa B alpha: evidence for an inducible autoregulatory pathway. Science 259, 1912-1915 (1993).

38. Bottero, V., Imbert, V., Frelin, C., Formento, J. L. \& Peyron, J. F. Monitoring NFkappa B transactivation potential via real-time PCR quantification of I kappa Balpha gene expression. Mol. Diagn. 7, 187-194 (2003).

39. Ayer, D. E., Lawrence, Q. A. \& Eisenman, R. N. Mad-Max transcriptional repression is mediated by ternary complex formation with mammalian homologs of yeast repressor Sin3. Cell 80, 767-776 (1995).

40. Dezfouli, S., Bakke, A., Huang, J., Wynshaw-Boris, A. \& Hurlin, P. J. Inflammatory disease and lymphomagenesis caused by deletion of the Myc antagonist Mnt in T cells. Mol. Cell Biol. 26, 2080-2092 (2006).

41. Link, J. M. et al. A critical role for Mnt in Myc-driven T-cell proliferation and oncogenesis. Proc. Natl Acad. Sci. USA 109, 19685-19690 (2012).

42. Lee, $\mathrm{H}$. et al. Role of Rel-related factors in control of c-myc gene transcription in receptor-mediated apoptosis of the murine B cell WEH 231 line. J. Exp. Med. 181, 1169-1177 (1995).
43. Gupta, S. et al. Constitutive activation and overexpression of NF-kappaB/c-Rel in conjunction with p50 contribute to aggressive tongue tumorigenesis. Oncotarget 9, 33011-33029 (2018).

44. Grumont, R. et al. The mitogen-induced increase in T cell size involves PKC and NFAT activation of Rel/NF-kappaB-dependent c-myc expression. Immunity 21, 19-30 (2004)

45. Slotta, C. et al. CRISPR/Cas9-mediated knockout of c-REL in HeLa cells results in profound defects of the cell cycle. PLoS ONE 12, e0182373 (2017).

46. Visekruna, A., Volkov, A. \& Steinhoff, U. A key role for NF-kappaB transcription factor c-Rel in T-lymphocyte-differentiation and effector functions. Clin. Dev. Immunol. 2012, 239368 (2012).

47. Guerrero, I., Pellicer, A. \& Burstein, D. E. Dissociation of c-fos from ODC expression and neuronal differentiation in a PC12 subline stably transfected with an inducible N-ras oncogene. Biochem. Biophys. Res. Commun. 150 1185-1192 (1988).

48. Walker, W., Zhou, Z. Q., Ota, S., Wynshaw-Boris, A. \& Hurlin, P. J. Mnt-Max to Myc-Max complex switching regulates cell cycle entry. J. Cell Biol. 169, 405-413 (2005)

49. Sanjabi, S. et al. A c-Rel subdomain responsible for enhanced DNAbinding affinity and selective gene activation. Genes Dev. 19, 2138-2151 (2005).

50. Lafita-Navarro, M. C. et al. MXD1 localizes in the nucleolus, binds UBF and impairs rRNA synthesis. Oncotarget 7, 69536-69548 (2016).

51. Garcia-Gutierrez, L. et al. Myc stimulates cell cycle progression through the activation of Cdk1 and phosphorylation of p27. Sci. Rep. 9, 18693 (2019).

52. Turriziani, B. et al. On-beads digestion in conjunction with data-dependent mass spectrometry: a shortcut to quantitative and dynamic interaction proteomics. Biology 3, 320-332 (2014).

53. Algarte, M., Kwon, H., Genin, P. \& Hiscott, J. Identification by in vivo genomic footprinting of a transcriptional switch containing NF-kappaB and Sp1 that regulates the IkappaBalpha promoter. Mol. Cell Biol. 19, 6140-6153 (1999).

54. Garcia-Sanz, P. et al. Sin3b interacts with myc and decreases myc levels. J. Biol. Chem. 289, 22221-22236 (2014). 